\title{
Oilseeds Crops: Agronomy, Science, and Technology
}

\author{
Mohamed Fawzy Ramadan Hassanien, ${ }^{1}$ Sascha Rohn, ${ }^{2}$ Hesham Farouk Oraby, ${ }^{3}$ \\ Bertrand Matthäus, ${ }^{4}$ and Abdalbasit Adam Mariod ${ }^{5}$ \\ ${ }^{1}$ Department of Biochemistry, Faculty of Agriculture, Zagazig University, Zagazig 44519, Egypt \\ ${ }^{2}$ Institut für Lebensmittelchemie, Hamburg University, Grindelallee 117, 20146 Hamburg, Germany \\ ${ }^{3}$ Cellulosic Biofuel Network, Soils and Crops Research and Development Center, Agriculture and Agri-Food Canada, Canada \\ ${ }^{4}$ Institute for Lipid Research, Federal Research Center for Nutrition and Food, Germany \\ ${ }^{5}$ Food Sciences and Technology Department, College of Agricultural Studies, Sudan University of Science \& Technology, \\ P.O. Box 71 Khartoum North, Sudan
}

Correspondence should be addressed to Mohamed Fawzy Ramadan Hassanien, hassanienmohamed@yahoo.com

Received 10 August 2012; Accepted 10 August 2012

Copyright (C) 2012 Mohamed Fawzy Ramadan Hassanien et al. This is an open access article distributed under the Creative Commons Attribution License, which permits unrestricted use, distribution, and reproduction in any medium, provided the original work is properly cited.

Oilseeds are expected to play an increasing role in future food supply. Even though the species are diverse, interestingly there are many varieties which possess potentials for food production. Various seeds are generally rich in lipids and provide the major part of oil and fat needs of the populations.

Major conventional edible vegetables oils and fats produced worldwide are generally provided by cotton, soy, sunflower, rapeseed, peanut, palm kernel, and cocoa seeds using traditional and industrial processes. In many countries traditional processes for producing oil are very important, especially among rural communities which have easy access to raw oleaginous materials. Traditional processing tends to be environmentally sound and the skills required are family or group activities. The lack of suitable conservation methods for the local oilseeds before processing limits the opportunity for export. Food conservation constitutes a primordial problem in the tropics where postharvest losses are estimated at more than $50 \%$. In large-scale production, refined oils are produced through development projects from raw materials like cottonseed using industrial operations. The edible oils obtained meet the requirements of urban consumers such as bland flavor and odor, clear appearance, light color, stability to oxidation, and suitability for frying.

While there are many uses for industrial vegetable oils, total world production is only about $3 \%$ of that of edible oils. Fats and oils are essential nutrients, comprising about $40 \%$ of the calories in the diet. Edible vegetable oils, margarine, and shortening are used food applications. These products supplement or replace animal products (e.g., butter and lard), supplies of which are inadequate to meet the needs of an increasing world population. On the other side, oilseed meals are rich in protein; mixed with other ingredients (e.g., cereal grains), they provide nutritionally balanced feeds.

Traditionally, the main non-food uses for fats and oils have been in the manufacture of soaps and detergents and in the production of greases, lubricants, and candles. More recently, the biofuels market has provided significant new, non-food use for edible oilseeds; it is used as the feedstock for the production of biodiesel and as an alternative to mineral oils for agricultural machinery. However, edible oilseeds are not in surplus supply and such raw materials for biodiesel are not useful from an economical point of view. Therefore, Jatropha curcas characterized by a rapid growth, low cost of seeds, and high oil content (ca. 50\%) has been successfully tested for biodiesel production.

Fats and oils as sources of carbon-carbon double bonds can undergo transformation by metathesis reaction to form intermediates, which could then be used for the synthesis of a wide range of reaction products ranging from pharmaceuticals and cosmetics to polymers and fine chemicals. In many countries, hectares of lands available as well as a favorable climate for the production of oil crops and for stock farming. These must be considered as new opportunities for the continent that is currently positioning itself to take a more proactive role in the global economy. 
Although a lot of literature is available on the physicochemical and nutritional characteristics of conventional vegetable oils and fats, very few researches based on nonconventional oil seeds for industry are made. In this special issue concerning oilseeds crops, international researchers contributed original research papers and review articles on potential topics including crop management, genetics and breeding, genomics and biotechnology, plant protection, quality and nutrition of seed oils, biofuels, and economics.

\section{Acknowledgment}

Special thanks are due to guest editors Professor Rohn Sascha, Dr. H. F. Oraby, Dr. B. Matthäus, and Dr. A. A. Mariod for efforts been made to review and edit the articles for this special issue.

Mohamed Fawzy Ramadan Hassanien Rohn Sascha Hesham Farouk Oraby Bertrand Matthäus Abdalbasit Adam Mariod 


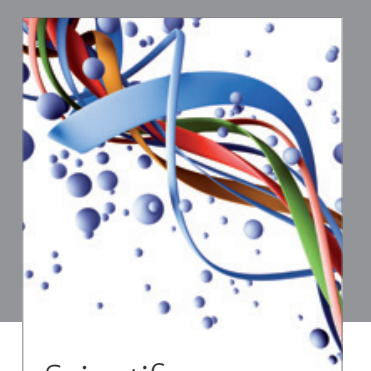

Scientifica
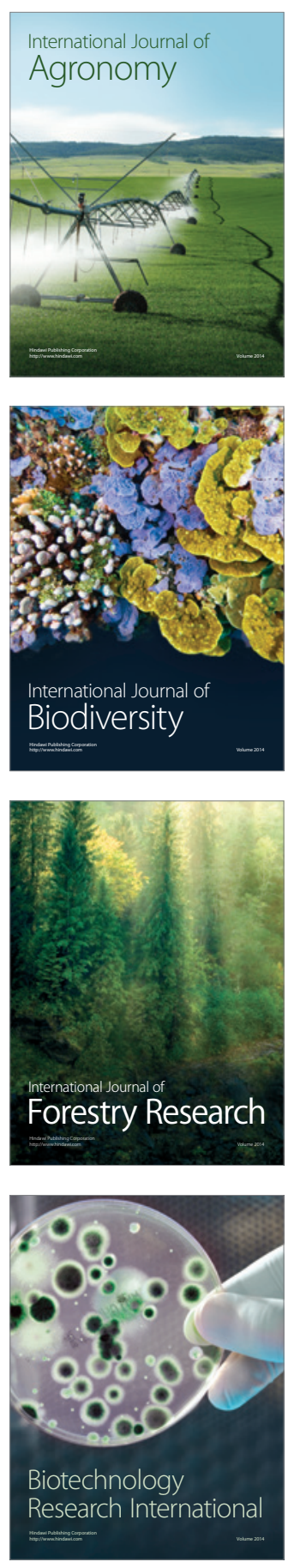
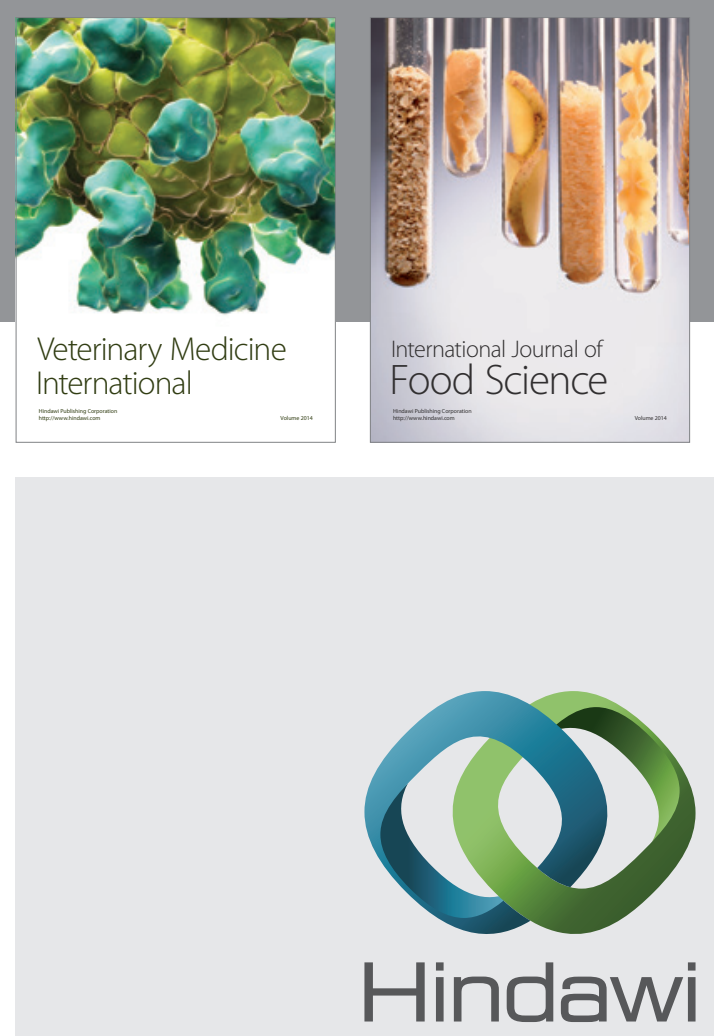

Submit your manuscripts at

http://www.hindawi.com
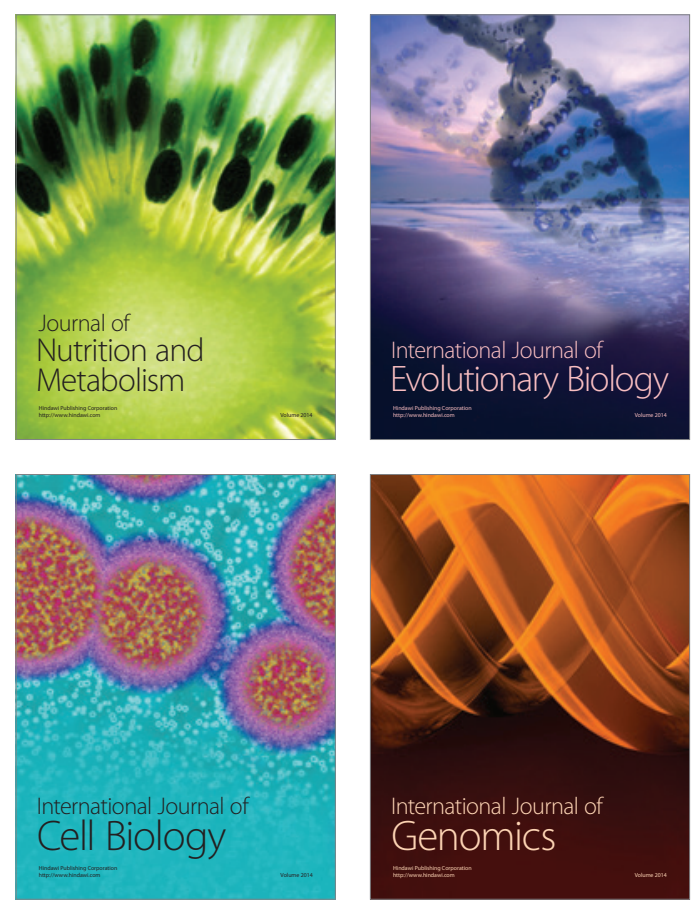
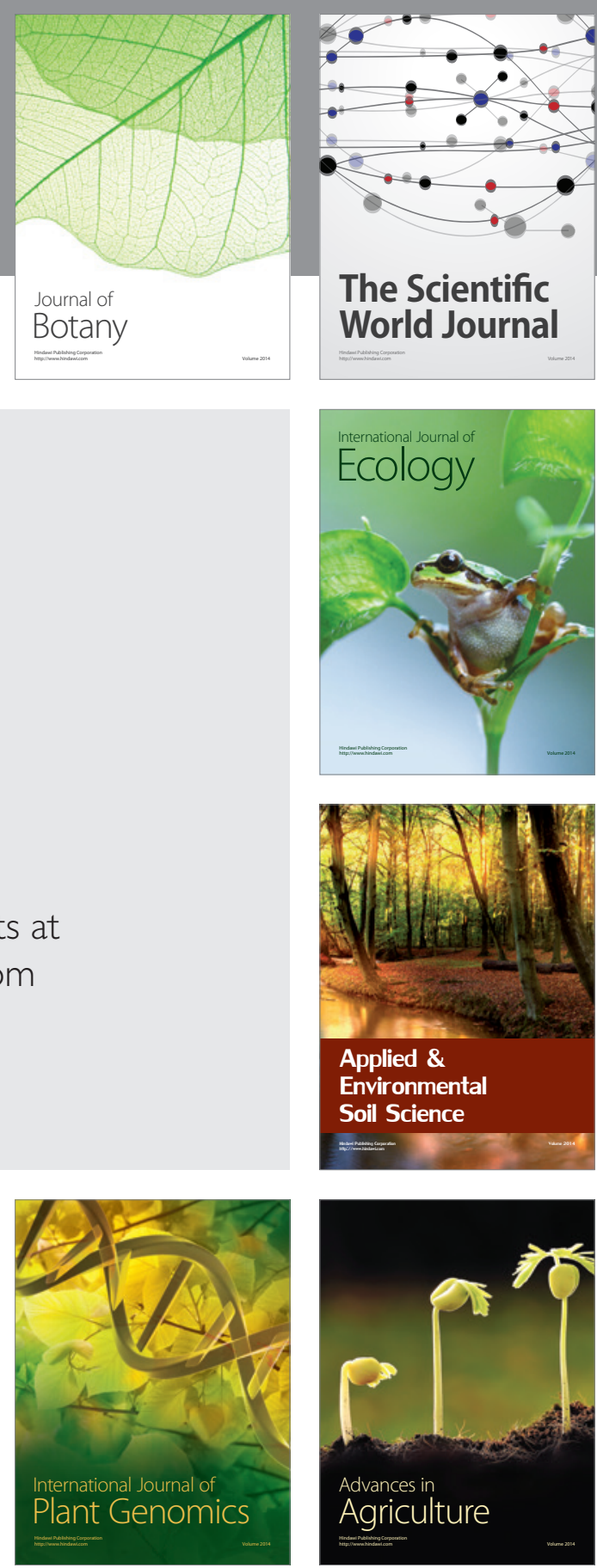

The Scientific World Journal
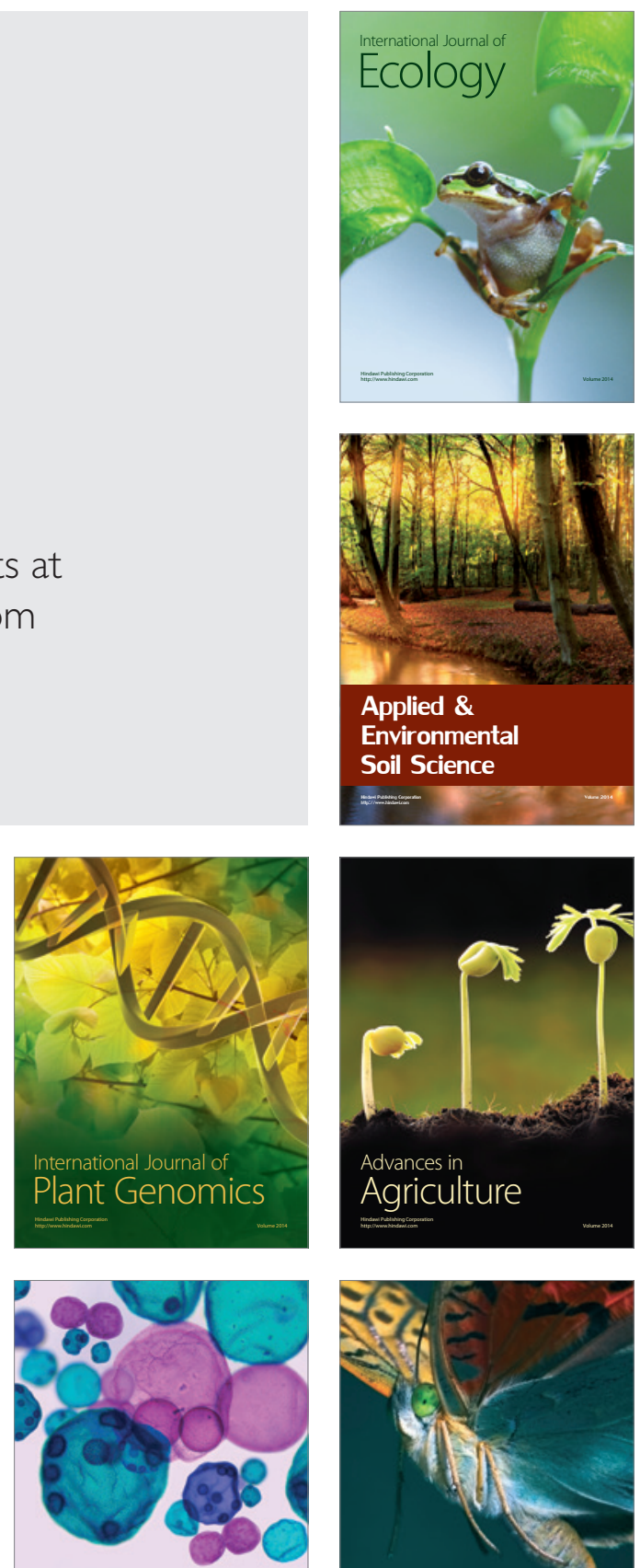

International Journal of Microbiology

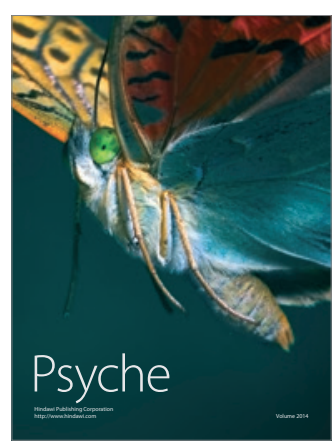

